\title{
Strategies and actions towards sustainability: Encouraging good ITS practices in the SUMP vision
}

Cite as: AIP Conference Proceedings 2343, 090008 (2021); https://doi.org/10.1063/5.0047897

Published Online: 30 March 2021

Vincenza Torrisi, Chiara Garau, Giuseppe Inturri, and Matteo Ignaccolo

Export citation

Challenge us.

What are your needs for periodic signal detection?

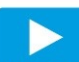

Watch

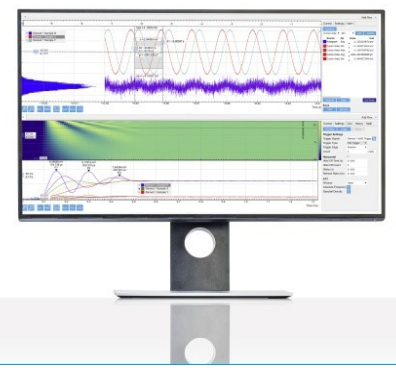

Zurich Instruments 


\title{
Strategies and Actions towards Sustainability: Encouraging Good ITS Practices in the SUMP Vision
}

\author{
Vincenza Torrisi $^{1, \text { a) }}$, Chiara Garau ${ }^{2, \text { b) }}$, Giuseppe Inturri ${ }^{3}$, Matteo Ignaccolo ${ }^{1}$ \\ ${ }^{1}$ Department of Civil Engineering and Architecture, University of Catania, Via S.Sofia 64, Catania, 95125, Italy \\ ${ }^{2}$ Department of Civil and Environmental Engineering and Architecture, University of Cagliari, 09129 Cagliari, Italy \\ ${ }^{3}$ Department of Electric, Electronic and Computer Engineering, University of Catania, Via S. Sofia 64, Catania, \\ 95125, Italy
}

a)Corresponding authors: vtorrisi@dica.unict.it ${ }^{\text {b) }}$ cgarau@unica.it

\begin{abstract}
Nowadays, cities are increasingly required to be smart, sustainable, resilient and adaptive and, particularly following the COVID-19 pandemic, an integrated approach to transport planning needs to be adopted. In fact, European policies have adopted a series of limitations in the transport sector that led the scientific community to put into question the traditional transport planning process, by accelerating processes close to sustainability, started some time ago. In fact, many efforts in terms of strategies, initiatives and research have been made in the last decade to enhance new forms of sustainable urban mobility, in order to reduce the externalities associated with the transport sector. To achieve this goal, the European Commission has emphasized the integrated planning at all mobility levels. Among the other instruments, it has been identified a key role in the writing of the Sustainable Urban Mobility Plan (SUMP), its management and also through Intelligent Transport Systems (ITS). Based on this premise, the aim of this paper is to present first results of a wider research aimed at investigating the methodological and practical approaches to boost the strategy of integration between transport systems and urban planning by using ITS technologies and infomobility systems. The research can support further investigations in order to define specific Key Performance Indicators (KPIs) to measure and monitoring the impacts of technologies on developing smart cities and promoting sustainable mobility approaches, facing the urban planning and transport mobility issues of modern society.
\end{abstract}

Keywords: Sustainable Mobility; Sustainable Urban Mobility Plan; PUMS; Intelligent Transport Systems, COVID-19.

\section{INTRODUCTION}

Since the beginning of 2020 following the COVID-19 pandemic, today's cities have had to adapt to emerging demands, becoming even more smart, sustainable and resilient [2,3], and re-inventing traditional urban and transport functions [4]. However, the COVID-19 pandemic has reshaped some processes already started. For instance, the transport sector had major repercussions and others issues were added to the more consolidated problems. Among the latter, it is important to underline that the transport sector generates a series of impacts on the surrounding systems with costs that are not directly perceived by the actors who satisfy their mobility needs, nevertheless representing a serious source of system inefficiencies. The attention towards the identification of these negative externalities has grown over time and takes on even more relevance in a historical period in which poor public resources require a careful evaluation of cost-benefits analysis deriving from planning processes and scheduling policies.

Literature review identifies four main external factors associated with mobility: atmospheric pollution, connected with emissions into the atmosphere by motor vehicles [5,6]; noise pollution, resulting from the population exposure to noise generated by both road, rail and air traffic, especially in the proximity of key infrastructural nodes $[7,8]$; accidents, especially associated to the road ones and congestion of infrastructural network with consequent loss of capacity linked to the additional time spent traveling compared to the optimal travel time $[9,10]$. Furthermore, the overall growth in movements, both related to people and goods, often based on the use of private vehicles determines an increase of these transport mobility impacts. The actual emergency situation caused by the COVID-19 pandemic, pushed this issue because on the one hand there is a reduction in the number of trips, but on the other

International Conference of Computational Methods in Sciences and Engineering ICCMSE 2020

AIP Conf. Proc. 2343, 090008-1-090008-8; https://doi.org/10.1063/5.0047897

Published by AIP Publishing. 978-0-7354-4088-3/\$30.00 
hand the public transport system has been thrown into crisis due to social distancing, taking consideration the private car as a safer transport modes. Therefore, it is necessary to define strategies for the enhancement of sustainable mobility in Europe and actions that make these strategies operational at local level. This perspective, which suggests the need to link the different levels of public policy-making, seems extremely necessary with regard to the urban dimension. Hence, the need to pursue a common strategy, to be applied at different levels, and which takes as a priority objective the enhancement of sustainable mobility.

Transport policy represents one of the main pillars of the European strategy on urban sustainability [11]. Looking at the instruments adopted by European Commission in the transport sector, guidelines first Guidelines have been defined in 1992 within the White Paper "on the future development of the common transport policy", which was subsequently updated by the White Paper in 2001. European transport policy for 2010: time to decide, and finally with the 2006 document Keeping Europe moving - Sustainable mobility for our continent. In 2007 the European Commission adopted the new Green Paper, specifically dedicated to urban mobility, "Towards a new culture of urban mobility, which is the reference for sustainable urban mobility policies". The European Commission identifies the Sustainable Urban Mobility Plan (SUMP), from Italian Piani Urbani della Mobilità Sostenibile (PUMS), as a strategic urban tool that orientates mobility in a sustainable way The SUMP "ensures a variety of sustainable transport options for the safe, healthy and fluid passage of people and goods, with all due consideration for fellow residents and the urban environment" [12].

Based on this premise, the aim of this paper is to present first results of a wider research aimed at investigating the methodological and practical approaches to boost the strategy of integration between transport systems and urban planning by using ITS technologies and infomobility systems. The structure of the paper consists of 4 sections: Section 1 initially introduced the transport sector externalities and the vision of legal planning tools promoting sustainability through the use of ITS technologies; Section 2 enhances the role of SUMP towards sustainability by emphasizing the role of ITS technologies; Section 3 focuses on ITS and their impact as enabling technologies to boost sustainable mobility concepts of SUMPs; Section 4 provides discussions about the viewing of ITS within the SUMPs and heads for conclusions and implications for future research.

\section{THE ROLE OF SUMPS TOWARDS SUSTAINABILITY}

The SUMP proposes an organic vision with strategic content that targets its forecasts over a long-term horizon, usually over a ten-year. The main purpose that this legal tool follows up is to reduce the environmental mobility costs and at the same time to allow adequate accessibility levels, characterizing a series of strategic actions to make operational policies related to urban mobility and sustainability [13]. This plan integrates comprehensive urban mobility projects, which collect and coordinate different mobility systems including all public and road transport infrastructure interventions, interchange parkings [14], requalification of walkable urban spaces [15,16,17] and cycling through integrated approaches [18,19], use of technologies [20,21], vehicles, policies for demand management, mobility managers structure, traffic control and regulation systems, information to users, logistics and technologies for optimizing the distribution of goods in cities $[22,23,24]$ in order to satisfy the mobility needs of residents and, more in general, of the city users [25]. The SUMP differs from the UMP (i.e. Urban Mobility Plan) for several elements including the participation which provides for the involvement of both stakeholders and citizens and the elaboration of implementation plans [26,27,28].

Among the contents of the plan there are also the objectives to be achieved and the indicators for evaluating the actions implemented by several instruments, establishing the guidelines for the next monitoring phase (Table 1). 
TABLE 1. Areas of intervention and associated objects of SUMPs (Source: Authors elaboration starting from [12,29,30])

\begin{tabular}{|c|c|}
\hline Areas of intervention & Objectives \\
\hline Local public Transport & $\begin{array}{l}\text { Improvements for the quality, safety, integration and accessibility of } \\
\text { public transport services, including the infrastructures }\end{array}$ \\
\hline Non-motorized transport & $\begin{array}{l}\text { Adaptation and improvement of existing infrastructures or creation of } \\
\text { new ones }\end{array}$ \\
\hline Intermodality & $\begin{array}{l}\text { Improve the integration between the various modes of transport and } \\
\text { multi-modes }\end{array}$ \\
\hline Road safety & Highlight the main problems related to road safety and risks \\
\hline Focus Sharing mobility & $\begin{array}{c}\text { Related to Coronavirus emergency } \\
\text { Related to use during last year }\end{array}$ \\
\hline Road transport & Optimize the use of the road even towards other modes or functions \\
\hline Urban logistics & $\begin{array}{l}\text { Improving the efficiency of logistics, reducing externalities in terms of } \\
\text { emissions, pollutants and noise }\end{array}$ \\
\hline Mobility Management & $\begin{array}{c}\text { Widen the audience of possible recipients: citizens, workers, students and } \\
\text { other relevant groups }\end{array}$ \\
\hline $\begin{array}{l}\text { Information Transportation } \\
\text { Systems }\end{array}$ & $\begin{array}{l}\text { Use technology for formulating strategies, implementing policies and } \\
\text { measures of sustainable mobility monitoring }\end{array}$ \\
\hline
\end{tabular}

In this context, it is extremely important to consider ITS for supporting cities. In fact, ITSs play a significant role in determining innovative sustainable transport, for a better use of urban space and time [31], with a multi-faceted approach based on the three pillars of sustainability: environmental, economic and social ones. Experiences in different countries, both in the US and in Europe, report that in several ITS applications the following results have been obtained: reduction of travel time of around $20 \%$, enhance the capacity of the network by $5-10 \%$, decrease in the number of accidents by $10-15 \%$, decrease congestion by $15-20 \%$, reductions in pollutant emissions by $10-15 \%$ and reduction of energy consumption by $12 \%$. [32].

\section{ENABLING TECHNOLOGIES THROUGH COOPERATIVE INTELLIGENT TRANSPORT SYSTEMS}

The application of ITS over the years has greatly changed since in the past they were used to ensure an improvement in traffic flows, in terms of service levels, encouraging the use of private means [33]. Today, the use of technology is to support smart cities and smart mobility searching to encourage the use of more sustainable alternative transport modes (e.g. public transport and soft mobility) and more in general enhancing quality of life [34]. Smart mobility aims to offer a seamless mobility experience, from the first to the last mile, which is flexible, integrated, safe, on-demand and convenient. The urban mobility can be innovated through new technologies and applications able to integrate public transport, better infrastructure [35,36] and all forms of sharing mobility [37]. The final purpose of introducing smart mobility in our cities is to reduce traffic and pollution, to create seamless and intelligent flows and to strengthen scale economies to promote accessibility to all [38].

In SUMPs, ITS are essential because they help to manage better the development of cities and ITS also help to use more efficiently infrastructures, vehicles, logistics platforms [39]. In order to serve SUMPs goals there are different ITS solutions that can collaborate to the achievement of sustainable mobility. In this regard, it is crucial to understand how these technologies operate and their effectiveness in relation to the sustainable goals they intend to pursue.

Table 2 lists the SUMPs goals from the general to the more specific one, classifying them by considering the three areas of sustainability. Nevertheless, it is evident the necessity to take into consideration the fact that some improvements towards one of these sustainable aspects (i.e. environmental, economic and social) can indirectly generates positive repercussions on others as well. 
TABLE 2. SUMPs goal classified from a sustainable perspective (Source: Authors elaboration starting from [12,29])

\begin{tabular}{lccc}
\hline \multicolumn{1}{c}{ SUMP goals } & Environmental & Economic & Social \\
\hline G1. Improve city liveability & $\mathrm{X}$ & $\mathrm{X}$ & $\mathrm{X}$ \\
\hline G2. Improve air quality & $\mathrm{X}$ & & \\
\hline G3. Reduce noise emissions & $\mathrm{X}$ & & $\mathrm{X}$ \\
\hline G4. Improve accessibility & & & $\mathrm{X}$ \\
\hline G5. Improve safety & & $\mathrm{X}$ & $\mathrm{X}$ \\
\hline G6. Reduce congestion & $\mathrm{X}$ & $\mathrm{X}$ & \\
\hline G7. Boost economic growth & & & $\mathrm{X}$ \\
\hline G8. Unlock spatial opportunities & & $\mathrm{X}$ & $\mathrm{X}$ \\
\hline G9. Seamless journeys & & $\mathrm{X}$ & $\mathrm{X}$ \\
\hline G10. Boost public transport & $\mathrm{X}$ & $\mathrm{X}$ & $\mathrm{X}$ \\
\hline G11. Boost active travel & $\mathrm{X}$ & $\mathrm{X}$ & \\
\hline G12. Boost electromobility & $\mathrm{X}$ & $\mathrm{X}$ & $\mathrm{X}$ \\
\hline G13. Better transport data & $\mathrm{X}$ & $\mathrm{C}$ & \\
\hline
\end{tabular}

According to these goals, Table 3 summarizes the ITS measures that can be used or implemented to support related strategies and actions. The first measure is one of the most common in cities (i.e. TMC), until to consider the most complex one (i.e. MaaS). These measures can be applied both to private and public transport sector, by addressing different stakeholders, i.e. end-users (U), transport companies $(C)$, enforcements (E) and municipalities and local authorities (A). Also in this case, the intervention of these measures can involve multiple stakeholders, and a further, and secondly further ones.

TABLE 3. ITS measures and its characterization (Source: Authors elaboration starting from [40,41])

\begin{tabular}{lc}
\hline \multicolumn{1}{c}{ ITS measures } & Stakeholders \\
\hline M1. Reactive traffic management and control (TMC) & $\mathrm{U} / \mathrm{C} / \mathrm{E}$ \\
\hline M2. Predictive traffic management and control & $\mathrm{C}$ \\
\hline M3. Public Transport and emergency vehicle priority & $\mathrm{C} / \mathrm{E}$ \\
\hline M4. Traveller information & $\mathrm{U} / \mathrm{C}$ \\
\hline M5. Parking management and information & $\mathrm{U} / \mathrm{C} / \mathrm{E}$ \\
\hline M6. Red light and parking enforcement & $\mathrm{C} / \mathrm{E}$ \\
\hline M7. Map and location referencing & $\mathrm{U} / \mathrm{C} / \mathrm{E}$ \\
\hline M8. Dynamic route guidance & $\mathrm{U} / \mathrm{C}$ \\
\hline M9. Floating vehicle data & $\mathrm{C} / \mathrm{M}$ \\
\hline M10. Road user charging & $\mathrm{U} / \mathrm{E} / \mathrm{A}$ \\
\hline M11. Fleet management systems & $\mathrm{C} / \mathrm{M}$ \\
\hline M12. Demand-responsive transport (DRT) & $\mathrm{U} / \mathrm{C}$ \\
\hline M13. E-ticketing & $\mathrm{U} / \mathrm{C}$ \\
\hline M14. E-payment & $\mathrm{U} / \mathrm{C}$ \\
\hline M15. Mobility as a Service (MaaS) & $\mathrm{U} / \mathrm{C} / \mathrm{M}$ \\
\hline
\end{tabular}

Table 4 shows the correlation between goals and measures, in applying a Likert scale based on four evaluation steps, from 0 (i.e. non-existent correlation), to 3 (i.e. highest correlation), with intermediate values 1 (i.e. very little) and 2 (moderate). This analysis allows to highlight the effectiveness of ITS in relation to the SUMPs, which is subsequently the object of in-depth analysis and measurement in the third phase of the SUMPs cycle. 
TABLE 4. Measure of ITS effectiveness towards the SUMP goals (Source: Authors elaboration starting from [42,43])

\begin{tabular}{|c|c|c|c|c|c|c|c|c|c|c|c|c|c|c|c|}
\hline & M1 & M2 & M3 & M4 & M5 & M6 & M7 & M8 & M9 & M10 & M11 & M12 & M13 & M14 & M15 \\
\hline G1 & 1 & 2 & 2 & 2 & 2 & 1 & 2 & 2 & - & 1 & 1 & 1 & 3 & 3 & 3 \\
\hline G2 & 1 & 2 & - & 2 & 1 & 1 & - & 1 & - & 3 & 2 & 1 & - & 3 & 1 \\
\hline G3 & 1 & 2 & - & 2 & 1 & - & - & - & - & 3 & 2 & 1 & - & - & 2 \\
\hline G4 & - & 2 & 1 & 1 & 1 & - & 3 & - & 1 & 1 & - & 3 & 2 & 2 & 3 \\
\hline G5 & 1 & 2 & 2 & 2 & - & 3 & - & 1 & - & 2 & - & - & 2 & 3 & - \\
\hline G6 & 1 & 2 & 2 & 2 & 1 & 2 & 1 & 2 & 1 & 3 & 2 & 2 & 1 & 2 & 2 \\
\hline G7 & 1 & 2 & 1 & 1 & 2 & 2 & - & - & - & 2 & 1 & 1 & 2 & 2 & 2 \\
\hline G8 & - & - & 3 & 2 & 3 & 2 & 1 & - & - & 3 & - & 1 & - & 2 & 3 \\
\hline G9 & 2 & 2 & 2 & 3 & 1 & 1 & 2 & 2 & 1 & 1 & - & 2 & 3 & 3 & 1 \\
\hline G10 & 1 & 2 & 3 & 2 & 1 & - & 2 & - & 1 & 1 & 3 & 3 & 2 & 2 & 1 \\
\hline G11 & - & - & - & 2 & - & 2 & 2 & - & - & 1 & - & - & 3 & - & 1 \\
\hline G12 & - & - & - & 2 & 1 & 1 & 2 & 1 & 1 & 2 & 1 & - & - & - & 2 \\
\hline G13 & 1 & 2 & 1 & 3 & 1 & 1 & 2 & 2 & 3 & 2 & 2 & 1 & 1 & 1 & 2 \\
\hline
\end{tabular}

\section{DISCUSSION AND CONCLUSIONS}

The topic of sustainable mobility in urban environments has acquired great centrality within legal planning tools at all levels. Moreover, there is growing attention towards urban quality which is strongly depending on the environmental performances that urban systems express. A satisfactory level of urban quality can ensure a healthy living environment for the inhabitants of European cities as well as greater overall competitiveness to the system since it is able to attract qualified functions and resources. Transport policies constitute one of the major foundations on which the European strategy on urban sustainability is based. In this regard, the SUMP represents a European legal tool, with its transposition at national level through PUMS, to achieve integrated planning at all mobility levels. The interest in transport urban policies is also to be traced back to the recent trends followed by the settlements which have tended to favor diffusion distribution methods on the territory with increasing motorized travels. Moreover, the current COVID-19 emergency, has emphasized and exasperated the use of private vehicle, especially in urban areas, as considered safer in relation to the social confinement. To face this emerging mobility issues, the role of smart mobility and ITS technologies has become even more fundamental to support actions and strategies towards the new transport mobility issues.

As emerged from the analysis, there are several measures to achieve the SUMPs goals. They may concern different strategies related to the demand mobility management, expansion of public transport, telematics, intermodality empowering soft mobility, urban logistics. The correlation between these measures and goals allowed to evaluate their effectiveness. The use of technologies associated to the road user charging and E-ticketing seems to represent the ITS measures with the best impact in term of effectiveness related to the SUMPs goals, since they obtained the maximum judgement for four of them. Road user charging, coinciding with "road pricing" or "congestion charging" meet the principle that "the user pays". It is an operational management policy developed in many countries but the main issue is associated to user acceptance. Several applications have been adopted, based on the use of on-board microwave transponder (e.g. in France, Singapore and Florida), or fitting an in-vehicle unit based on GPS (e.g. in Germany), or using recognition cameras (e.g. in London). E-ticketing represents innovations in ticketing that have also coincided with innovation in payment technologies (E-payment). There are based on the use of smart cards or credit cards with different forms of pricing policies (e.g. single journey, pay-as-you-go, weekly or monthly travel pass). The associated advantages see reduced costs of handling cash, reduced fraud, increased business data available in real-time, greater flexibility in ticket pricing and implementing changes to fares. The development of a "universal" card constitutes the base for an interoperable package, which Maas requires.

In terms of spread of uses with respect to the satisfaction of these goals, there are road user charging and traveller information. The last one is able to deliver timely and accurate information to public transport passengers, drivers, travel planners and fleet managers so that route and mode choices can be adjusted in the light of the information. Traveller information systems generally receive data from other services and communicate to road users, representing a key element of an overall mobility demand management strategy. Both of these two measures are able to produce effects that can be associated with each goal as they provide outputs intended for the end-user in the logic of human-centered approach of SUMPs. Instead, as regards the measure relating to floating vehicle data, it 
performs a more targeted action, presenting a high efficacy in terms of congestion reduction and unlock of spatial opportunities. They often referred to as "probe vehicle data" which provide network managers details of traffic speeds at different places in the network. Therefore, even if the impact is not directly on the end-user, they represent a valid support for the provision of subsequent services. It is clear that the assimilation of the interventions listed above to the SUMP must also be established in relation to the organic nature and overall integration of the planned actions, given that it is a tool that preferentially deals with mobility in urban area and which is called "plan". Therefore, the more systemic the proposed vision is, both in terms of transport methods and in relation to the territorial context or the suburban areas, the greater the similarity that can be established with the SUMP.

The findings of this work create the basis for further research that will focus on the analysis of SUMPs and PUMS case studies, in order to assess the added-value given by the use of ITS technologies and to define specific Key Performance Indicators (KPIs) to measure and monitoring the effects of implemented actions and their impacts on developing smart cities and promoting sustainable mobility approaches, facing the urban planning and transport mobility issues of modern society.

\section{ACKNOWLEDGMENTS}

This work has been partially financed by the MIUR (Ministry of Education, Universities and Research [Italy]) through a project entitled WEAKI TRANSIT: WEAK-demand areas Innovative TRANsport Shared services for Italian Towns (Project code: 20174ARRHT; CUP Codes: E44I17000050001, F74I19001290001), financed with the PRIN 2017 (Research Projects of National Relevance) programme. We authorize the MIUR to reproduce and distribute reprints for Governmental purposes, notwithstanding any copyright notations thereon. Any opinions, findings and conclusions or recommendations expressed in this material are those of the authors, and do not necessarily reflect the views of the MIUR. This study was supported by the University of Catania within the project "Piano della Ricerca Dipartimentale 2016-2018" of the Department of Civil Engineering and Architecture and the project "Piano per la Ricerca 2016-2018 - Linea di intervento 2" of the Department of Electric, Electronic and Computer Engineering. This study was supported by the project "Urban Polarities in the Cities of Newcastle (UK) and Cagliari (Italy) for monitoring the central and attractive effects of the city-territory", founded by the programme "Bando 2019 Mobilità Giovani Ricercatori (MGR)", financed by the Autonomous Region of Sardinia (under the Regional Law of 7 August 2007, n. 7 "Promotion of Scientific Research and Technological Innovation in Sardinia").

\section{REFERENCES AND NOTES}

1. This paper is the result of the joint work of the authors. 'Abstract' and 'the role of SUMPS towards sustainability' were written jointly by V.T. and C.G. V.T. wrote 'Enabling technologies through cooperative Intelligent Transport Systems' and the 'Discussion and conclusions'. C.G. wrote the'Introduction'; M.I. and G.I. coordinated the research.

2. Azzari, M., Garau, C., Nesi, P., Paolucci, M., \& Zamperlin, P. (2018, May). Smart city governance strategies to better move towards a smart urbanism. In International Conference on Computational Science and Its Applications (pp. 639-653). Springer, Cham.

3. Garau, C., Desogus, G., \& Coni, M. (2019). Fostering and Planning a Smart Governance Strategy for Evaluating the Urban Polarities of the Sardinian Island (Italy). Sustainability, 11(18), 4962.

4. Megahed, N. A., \& Ghoneim, E. M. (2020). Antivirus-built environment: Lessons learned from Covid-19 pandemic. Sustainable Cities and Society, 102350.

5. Macedo, E., Tomás, R., Fernandes, P., Coelho, M. C., \& Bandeira, J. M. (2020). Quantifying road traffic emissions embedded in a multi-objective traffic assignment model. Transportation Research Procedia, 47, 648-655.

6. Fernandes, P., Vilaça, M., Macedo, E., Sampaio, C., Bahmankhah, B., Bandeira, J. M., ... \& Borrego, C. (2019). Integrating road traffic externalities through a sustainability indicator.Science of the total environment, 691, 483-498.

7. Fernandes, P., Tomas, R., Acuto, F., Pascale, A., Bahmankhah, B., Guarnaccia, C., ... \& Coelho, M. C. (2020). Impacts of roundabouts in suburban areas on congestion-specific vehicle speed profiles, pollutant and noise emissions: An empirical analysis. Sustainable Cities and Society, 102386.

8. Tesoriere, G., Campisi, T., Canale, A., \& Severino, A. (2018, November). The effects of urban traffic noise on children at kindergarten and primary school: A case study in Enna. In AIP Conference Proceedings (Vol. 2040 , No. 1, p. 140005). AIP Publishing LLC.

9. Torrisi, V., Ignaccolo, M., \& Inturri, G. (2017). Estimating travel time reliability in urban areas through a dynamic simulation model. Transportation Research Procedia, 27, 857-864. doi:10.1016/j.trpro.2017.12.134 
10. Torrisi, V., Ignaccolo, M., \& Inturri, G. (2017). Analysis of road urban transport network capacity through a dynamic assignment model: validation of different measurement methods. Transportation Research Procedia, 27, 1026-1033. doi:10.1016/j.trpro.2017.12.135

11. Cruz, I. S., \& Katz-Gerro, T. (2016). Urban public transport companies and strategies to promote sustainable consumption practices. Journal of Cleaner Production, 123, 28-33.

12. Torrisi V., Garau, C., Ignaccolo M., Inturri G., (in press) "Sustainable Urban Mobility Plans": key concepts and a critical revision on SUMPs guidelines" In: Gervasi O., Murgante B., Misra S., Garau C., Blecic I., Taniar D., Apduhan B. O., Rocha A. M. A. C., Tarantino E., Torre C. M., Karaca Y. (Eds.). Computational Science and Its Applications - ICCSA 2020. ICCSA 2020. Lecture Notes in Computer Science

13. May, A. D. (2015). Encouraging good practice in the development of Sustainable Urban Mobility Plans. Case studies on transport policy, 3(1), 3-11.

14. Campisi T., Ignaccolo M., Inturri G., Tesoriere G., Torrisi V., (in press) "The growing urban accessibility: a model to measure the car sharing effectiveness based on parking distances" In: Gervasi O., Murgante B., Misra S., Garau C., Blecic I., Taniar D., Apduhan B. O., Rocha A. M. A. C., Tarantino E., Torre C. M., Karaca Y. (Eds.). Computational Science and Its Applications - ICCSA 2020. ICCSA 2020. Lecture Notes in Computer Science

15. Campisi, T., Canale, A., \& Tesoriere, G. (2018, November). SWOT analysis for the implementation of spaces and pedestrian paths at the street markets of Palermo. In AIP Conference Proceedings (Vol. 2040, No. 1, p. 140003). AIP Publishing LLC.

16. Campisi, T., Canale, A., \& Tesoriere, G. (2019). The development of walkability in the historic centre of Enna: the case of the Saint Tommaso neighbourhood. European transport: international journal of transport economics, engineering \& law, (73), e4-e4.

17. Ignaccolo, M., Inturri, G., Giuffrida, N., Le Pira, M., Torrisi, V., \& Calabrò, G. (2020). A step towards walkable environments: spatial analysis of pedestrian compatibility in an urban context. European Transport $\backslash$ Trasporti Europei, vol. 76 (6), p.1-12

18. Campisi, T., Acampa, G., Marino, G., \& Tesoriere, G. (2020). Cycling Master Plans in Italy: The I-BIM Feasibility Tool for Cost and Safety Assessments. Sustainability, 12(11), 4723.

19. Ignaccolo, C., Giuffrida, N., \& Torrisi, V. (2018). The queensway of New York city. A proposal for sustainable mobility in queens. Town and Infrastructure Planning for Safety and Urban Quality, 69-76. doi:10.1201/9781351173360-12

20. Torrisi, V., Ignaccolo, M., \& Inturri, G. (2018). Toward a sustainable mobility through a dynamic real-time traffic monitoring, estimation and forecasting system: The RE.S.E.T. project. Town and Infrastructure Planning for Safety and Urban Quality - Proceedings of the 23rd International Conference on Living and Walking in Cities, LWC 2017, pp. 241-247. doi:10.1201/9781351173360-32

21. Torrisi, V., Ignaccolo, M., \& Inturri, G. (2018, May). Innovative Transport Systems to Pomote Sustainable Mobility: Developing the Model Architecture of a Traffic Control and Supervisor System. In International Conference on Computational Science and Its Applications (pp. 622-638). Springer, Cham. doi:10.1007/978-3-319-95168-3 42

22. Calabrò, G., Torrisi, V., Inturri, G., \& Ignaccolo, M. (2020). Improving inbound logistic planning for large-scale real-world routing problems: a novel ant-colony simulation-based optimization. European Transport Research Review, 12(1). doi:10.1186/s12544-020-00409-7

23. Ignaccolo, M., Inturri, G., Giuffrida, N., Torrisi, V., \& Cocuzza, E. (2020). Sustainability of Freight Transport through an Integrated Approach: the Case of the Eastern Sicily Port System. Transportation Research Procedia, 45, 177-184. doi:10.1016/j.trpro.2020.03.005

24. Ignaccolo M., Inturri G., Giuffrida N., Torrisi V., 2020. A Sustainable Framework for the Analysis of Port Systems. European transport: international journal of transport economics, engineering \& law, (78), Paper $n^{\circ} 7, I_{S S N}$ 1825-3997

25. Bezerra, B. S., dos Santos, A. L. L., \& Delmonico, D. V. (2020). Unfolding barriers for urban mobility plan in small and medium municipalities-A case study in Brazil. Transp. Research Part A: Policy and Practice, 132, 808-822.

26. Ignaccolo, M., Inturri, G., Giuffrida, N., Pira, M. L., \& Torrisi, V. (2019). Public Engagement for Designing New Transport Services: Investigating Citizen Preferences from a Multiple Criteria Perspective. Transportation Research Procedia, 37, 91-98. doi:10.1016/j.trpro.2018.12.170

27. Campisi, T., Akgün, N., Ticali, D., \& Tesoriere, G. (2020). Exploring Public Opinion on Personal Mobility Vehicle Use: A Case Study in Palermo, Italy. Sustainability, 12(13), 5460.

28. Ignaccolo, M., Inturri, G., Giuffrida, N., Le Pira, M., \& Torrisi, V. (2017). Structuring transport decision-making problems through stakeholder engagement: The case of Catania metro accessibility. Transport Infrastructure and Systems, 919-926. doi:10.1201/9781315281896-118

29. ELTIS. http://www.eltis.org/mobility-plans/project-partners/civitas-sumps (accessed on 12 July 2020).

30. Ministerial Decree 4/8/2017, Guidelines fro the drafting of PUMS 
31. Coni, M., Garau, C., \& Pinna, F. (2018). How has Cagliari changed its citizens in smart citizens? Exploring the influence of ITS technology on urban social interactions. In International Conference on Computational Science and Its Applications (pp. 573-588). Springer, Cham.

32. European Commision, Directive 2010/40/UE (2010)

33. Żochowska, R., \& Karoń, G. (2016). ITS services packages as a tool for managing traffic congestion in cities. In Intelligent Transportation Systems-Problems and Perspectives (pp. 81-103). Springer, Cham.

34. Di Pierro, E., Serravallo, S., \& Scorza, F. (2019, July). Integrated Public Transport Planning for Urban Sustainable Development in Potenza Town. In International Conference on Computational Science and Its Applications (pp. 331-346). Springer, Cham.

35. Acampa, G., Marino, G., \& Ticali, D. (2019). Validation of infrastructures through BIM. Paper presented at the AIP Conference Proceedings, , 2186 doi:10.1063/1.5138079

36. Acampa, G., Contino, F., Grasso, M., \& Ticali, D. (2019). Evaluation of infrastructure: Application of TOD to catania underground metro station. Paper presented at the AIP Conference Proceedings, 2186 doi:10.1063/1.5138078

37. Campisi, T., Torrisi, V., Ignaccolo, M., Inturri, G., \& Tesoriere, G. (2020). University propensity assessment to car sharing services using mixed survey data: the Italian case study of Enna city. Transportation Research Procedia, 47, 433-440. doi:10.1016/j.trpro.2020.03.155

38. Acampa, G., Grasso, M., Marino, G., \& Parisi, C. M. (2020). Tourist flow management: Social impact evaluation through social network analysis. Sustainability (Switzerland), 12(2) doi:10.3390/su12020731

39. Iliopoulou, C., Konstantinidou, M. A., Kepaptsoglou, K. L., \& Stathopoulos, A. (2020). ITS Technologies for Decision Making during Evacuation Operations: A Review. Journal of Transportation Engineering, Part A: Systems, 146(4), 04020010.

40. Sjoberg, K., Andres, P., Buburuzan, T., \& Brakemeier, A. (2017). Cooperative intelligent transport systems in Europe: Current deployment status and outlook. IEEE Vehicular Technology Magazine, 12(2), 89-97.

41. Hamida, E. B., Noura, H., \& Znaidi, W. (2015). Security of cooperative intelligent transport systems: Standards, threats analysis and cryptographic countermeasures. Electronics, 4(3), 380-423.

42. Collaborative cApacity Programme on ITS Training-educAtion and Liaison (CAPITAL), EU Funded Project, url: http://capital-project.its-elearning.eu/

43. Accelerating C-ITS Mobility Innovation and Deployment in Europe (C-MobILE), EU funded Project, url: https://cmobile-project.eu/ 